Mitteilungen der Österreichischen Geographischen Gesellschaft,

155. Jg. (Jahresband), Wien 2013, S. 148-170

\title{
Ungarische Migranten in Ungarn: Deserteure, Studierende und Berufstätige aus der WOIWODINA ZWISCHEN TRANSNATIONALER UND ETHNischer Migration ${ }^{1)}$
}

Béla FileP, Bern, Monika M. VÁrAdi, Budapest, Zoltán TAKÁcs, Subotica, Ágnes Erőss, Budapest, Imre NAgY, Novi Sad, Patrik TÁTrAi, Budapest, und Doris WAstL-WALTER, Bern*

\section{INHALT}

Summary

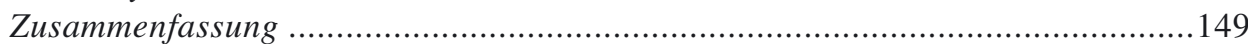

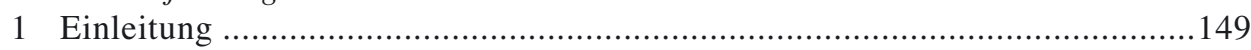

2 Von der Flucht vor der Einberufung in die jugoslawische Armee zur Arbeits- und Bildungsmigration

3 Generationelle Unterschiede unter den Migranten und die Rolle der Familie

4 Die Woiwodina-Ungarn in Ungarn - transnationale Migranten?

5 Idealtypen der grenzüberschreitenden Migration und der Lebenssituationen von Migranten.....

6 Ethnische Migration - aus dem Minderheitendasein ausbrechen? .....................161

7 Ethnische Migration und das Verhältnis zu Herkunftsland und „Mutterland“..165

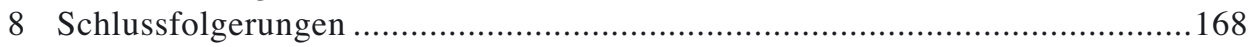

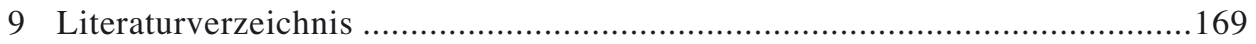

\footnotetext{
1) Die Autorenschaft bedankt sich beim Schweizerischen Nationalfonds SNF für die finanzielle Unterstützung des Projekts „Integrating (trans)national migrants in transition states (TransMig)“ (IZ73Z0_128097) im Rahmen des SCOPES-Forschungsprogramms. Die Resultate aus dem Projekt wurden an verschiedenen Stellen publiziert. Einige Ausführungen in diesem Beitrag erschienen auch auf Ungarisch in der Einleitung zu einem Sonderband der Zeitschrift „Tér és Társadalom“.

* Dr. Béla FileP und Prof. Dr. Doris WastL-W ALTER, Geographisches Institut, Universität Bern, Hallerstrasse 12, CH-3012 Bern; E-Mail: bfilep@giub.unibe.ch, dwastl@giub.unibe.ch; Dr. Monika VÁRADI, Institut für Regionalforschung, Ungarische Akademie der Wissenschaften, Budaörsi út 45, H-1112 Budapest; E-Mail: varadim@mta-rkk-tko.hu; Zoltán TAKÁCS, Wissenschaftliche Gesellschaft für Ungarnforschung, Branislava Nušića 2/1, SR-24000 Subotica; E-Mail: takac.zoltan@gmail.com; Ágnes ERőss und Dr. Patrik TÁtraI, Geographisches Forschungsinstitut, Ungarische Akademie der Wissenschaften, Budaörsi út 45, H-1112 Budapest; E-Mail: agnes.eross@gmail.com, tatraipatrik@gmail.com; Prof. Dr. Imre NAGY, Institut für Geographie, Tourismus und Hotelmanagement, Universität Novi Sad, Trg Dositeja Obradovića 3a, SR-21000 Novi Sad; E-Mail: nagyi@rkk.hu
} 


\section{Summary}

Hungarian migrants in Hungary: Deserters, students and professionally active persons from Vojvodina between transnational and ethnic migration

This paper deals with the short-and long-term consequences of the Yugoslav Wars on the emigration of Hungarians from Vojvodina to Hungary. We will show how the motives for emigration have changed over the last 20 years, from escape from the wars to labour migration during the economic crisis to a consciously chosen strategy of educational migration in the past decade. We analyse how the migrants reconstruct their migration stories and how they perceive them, how they deal with migration and what effect it has had on their identity construction. Finally, we put special emphasis on the question, whether these forms of migration can be understood as transnational migration with its respective transnational lifestyles or whether it is ethnic migration, in the framework of which Hungarians from the neighbouring states, return' to their motherland, as it is often described.

\section{Zusammenfassung}

Dieser Beitrag befasst sich mit den kurz- und langfristigen Folgen der Jugoslawienkriege für die Emigration von Ungarn aus der Woiwodina [Vojvodina] nach Ungarn. Wir zeigen auf, wie sich die Motive für die Emigration über die letzten 20 Jahre verändert haben, von der Flucht während der Kriege über die Arbeitsmigration während der Krise zur bewusst gewählten Strategie der Bildungsmigration im vergangenen Jahrzehnt. Wir analysieren, wie die Migranten ihre Migrationsgeschichte rekonstruieren und diese wahrnehmen, wie sie mit der Migration umgehen und wie sich die Migration auf die Konstruktion ihrer Identität ausgewirkt hat. Schließlich legen wir besonderes Augenmerk auf die Frage, ob diese Formen der Migration als transnationale Migration mit entsprechenden transnationalen Lebensformen verstanden werden können oder ob es sich um ethnische Migration handelt, im Rahmen derer die Auslandsungarn ins „,Vaterland ${ }^{2)}$ zurückkehren “, wie dies oft dargestellt wird.

\section{Einleitung}

Für ungarische Staatsbürger war Jugoslawien zu sozialistischen Zeiten die Brücke, für manche gar das Tor zum „Westen“. Bereits in den 1960er Jahren nahm der Grenzverkehr zwischen Ungarn und Jugoslawien zu und mit einem Abkommen über den „Kleinen Grenzverkehr“ in den 1970er Jahren erhöhte sich die Bewegungsfreiheit

\footnotetext{
2) Im Ungarischen entspricht der Begriff anyaország (Mutterland) dem deutschen Vaterland. Er ist - ebenso wie der Begriff Heimat - im Gegensatz zum Deutschen auch nicht historisch belastet. Da die Interviewpartner im ungarischen Original Mutterland gebrauchen, haben wir diese Metapher in den Interviews beibehalten.
} 
insbesondere für ungarische Staatsbürger. Die in der Grenzregion in einem Umkreis von $30 \mathrm{~km}$ wohnhafte Bevölkerung durfte fortan unbeschränkt nach Jugoslawien reisen; besonders die Woiwodina [Vojvodina] war beliebt für Reisen zwecks Einkaufs „westlicher“ Waren, die in Ungarn nicht erhältlich waren.

Auf der anderen Seite nutzten jugoslawische Staatsbürger die günstigeren Dienstleistungen in Ungarn. Ein ungarischer Lehrer aus Subotica/Szabadka in der Woiwodina erzählt, wie die Lehrerkollegen aus Szeged vor dem jährlich stattfindenden, gemeinsamen Fussballspiel ,,in die hiesigen Schallplattenläden gingen, als man hier westliche Schallplatten kaufen konnte, die es in Ungarn nicht gab, und auch andere Ware, die eher westlich war ".3) Die Ungarn in der Woiwodina waren für die Ungarn in Ungarn die progressiven, die dem ,westlichen Fortschritt“ näheren; sie konnten sich in Europa frei bewegen, sie hatten Zugang zu westlichen Gütern, während man in Ungarn von der (westlichen) Außenwelt abgeschnitten war.

Mit dem Fall des Eisernen Vorhangs und den zeitlich darauffolgenden Jugoslawienkriegen änderte sich dieses Bild schlagartig. Nun war es Ungarn, das dem „Westen“ näher war, das sich dem „Westen“, der Europäischen Union annäherte, während im ehemaligen Jugoslawien Krieg herrschte und die Bundesrepublik Jugoslawien (hier Serbien) durch die UNO-Embargos von der Außenwelt abgeschnitten war. Nun war Ungarn Brücke oder Tor zum Westen und für viele Ungarn, besonders in der Woiwodina, zugleich auch Zufluchtsort während der Kriege. Zwar war die Provinz in den 1990er Jahren nur marginaler Kriegsschauplatz, viele ungarische Männer wollten jedoch nicht an einem von Serbien geführten Krieg teilnehmen und desertierten ins grenznahe Ungarn. Das minderheitenfeindliche und das sich rasant verschlechternde wirtschaftliche Klima in Serbien führten gleichfalls zu vermehrter Emigration, welche sich bis in das 21. Jh. zieht, auch wenn die aktuellen Migrationsformen wie die Arbeits- und Bildungsmigration langfristig und nicht unmittelbare Konsequenzen der Jugoslawienkriege sind.

In diesem Beitrag, der auf Feldforschung und Interviews im ungarisch-serbischen Grenzraum basiert, zeigen wir sowohl die kurzfristigen als auch die langfristigen Auswirkungen der Jugoslawienkriege am Beispiel der ungarischen Flüchtlinge und Migranten aus der Woiwodina auf. Denn während die Flüchtlings- und Migrationsströme von Serben, Kroaten, Bosniaken und Albanern in der Literatur breit behandelt worden sind, wurde den Ungarn außerhalb des woiwodinischen Wissenschaftskontexts kaum Beachtung geschenkt. Das Beispiel der Woiwodina-Ungarn ist auch deshalb spannend, weil sich die Emigration nach Ungarn, seit 2004 ein EU-Mitgliedsstaat,

\footnotetext{
3) Die in diesem Beitrag zitierten Interviews wurden im Rahmen des SCOPES-Forschungsprojekts „Integrating (trans)national migrants in transition states (TransMig)“(2010-2013) des Schweizerischen Nationalfonds SNF geführt. An diesem Projekt waren die folgenden Wissenschafterinnen und Wissenschafter beteiligt: Doris Wastl-Walter und Béla FILEP vom Geographischen Institut der Universität Bern, Monika VÁRADI und Katalin RÁcZ vom Institut für Regionalforschung der Ungarischen Akademie der Wissenschaften (UAW), Károly Kocsis, Patrik TÁtrai und Ágnes ERőss vom Geographischen Forschungsinstitut der UAW, Zoltán TAKÁcs, Eszter GÁBrity und Irén GÁBRITY Molnár von der Wissenschaftlichen Gesellschaft für Ungarnforschung in Subotica/Szabadka sowie Saša KICOŠEv und Imre NAGY vom Institut für Geographie, Tourismus und Hotelmanagement sowie Dušan Ristić vom Institut für Soziologie der Universität Novi Sad.
} 
seit den Kriegen verändert hat: War während der Kriege die Flucht der Hauptgrund, ist die Bildungsmigration von heute unter den Jugendlichen vor allem ein Teil der Karriereplanung. Dadurch ergeben sich hinsichtlich der Migrationsgeschichte generationelle Unterschiede unter den migrierten Woiwodina-Ungarn und das Weggehen von „Zuhause“ hat eine andere Bedeutung.

Auch in zeitlich-räumlicher Hinsicht gibt es eine Vielzahl von Lebensentwürfen, die selbst im Einzelfall dynamisch sein können. Auf die Frage, ob und wann sich jemand für einen Verbleib in Ungarn oder eine Rückkehr in die Woiwodina entscheidet oder ob auch über längere Zeit ein Leben an mehreren Orten geführt wird, gibt es viele Antworten.

Schließlich ist der Fall der Woiwodina-Ungarn auch deshalb interessant, weil selbst wenn viele Elemente einer transnationalen Migration beobachtbar sind, die Migration von Ungarn aus der Woiwodina nach Ungarn oft vielmehr als intra-nationale denn als trans-nationale Migration konzeptualisiert werden kann. Denn die Migration wird als Migration ins „Vaterland“ oder auch als ethnische Migration verstanden. Die ungarischen Migranten aus der Woiwodina ziehen zwar in ein anderes, nicht aber in ein fremdes Land - sie sprechen die Sprache und fühlen sich kulturell nahe. So haben sie auf dem Bildungs- und Arbeitsmarkt entsprechend bessere Chance als andere, die im eigentlichen Sinne trans-nationale Migranten sind. Dennoch bleibt die ethnische Migration nicht ohne Spannungen, sei es aufgrund der Distanz zum Herkunftsland, zu Familie und Freunden und der nicht immer einfachen Anpassung an ein neues soziales Umfeld oder aufgrund der Erfahrung des „Othering“, da man gelegentlich dennoch als fremd wahrgenommen wird.

Wir diskutieren und analysieren in dieser Reihenfolge die unterschiedlichen Prozesse und Phänomene, welche die Migration der Woiwodina-Ungarn seit Beginn der Jugoslawienkriege charakterisieren.

\section{Von der Flucht vor der Einberufung in die jugoslawische Armee zur Arbeits- und Bildungsmigration}

Die erste Migrationswelle aus der Woiwodina nach Ungarn stand in unmittelbarem Zusammenhang mit den Jugoslawienkriegen in den 1990er Jahren. Tausende ethnisch ungarische Männer flüchteten vor der Einberufung in die jugoslawische Armee, zumeist nach Ungarn. In den Interviews erzählten uns Deserteure und ihre Angehörigen, wie sich die Männer zuhause versteckt hielten, damit man sie nicht fand, wenn die Gemeindevertreter mit der Einberufung kamen. Wochen- und monatelang hätten sie bei „des Anderen Frau“ geschlafen; und waren sie gerade zuhause, als man nach ihnen fragte, öffnete die Frau die Tür und verleugnete ihren Mann. Die Mehrheit hatte die Übersiedlung nach Ungarn nicht geplant, sondern oft von einem Tag auf den anderen entscheiden müssen und sich aufgemacht, um auf zum Teil ,,abenteuerlichem“ Weg die Grenze nach Ungarn zu überqueren. Die Geschichte eines Ingenieurs und seiner Familie steht hier stellvertretend für viele: 
An einem Nachmittag im Oktober 1991 saßen der eben aus der Arbeit zurückgekehrte Mann und seine Ehefrau beim Kaffee auf der Terrasse. Ihr Haus hatten sie vor nicht allzu langer Zeit fertiggestellt, er hatte einen guten Job, die Frau war Lehrerin in der Gemeinde. Von den beiden Töchtern war eine noch im Kindergarten, sie schrie damals im Sandkasten spielend gelegentlich auf, wenn die Richtung Vukovar tief fliegenden Bomber vorbeizogen. Der gemeinsame Kaffee auf der Terrasse wurde von einem Klingeln unterbrochen, die Frau ging zur Tür; ihr Mann sei nicht zuhause, sagte sie dem Gemeindevertreter, welcher die Einberufung in die Armee brachte. Aufgrund der Größe der Gemeinde, in der jeder jeden kannte, wusste er, dass die Frau nicht die Wahrheit sagte, er ging dennoch wieder. Die Familie entschied schnell, der Mann packte seine Sachen und verabschiedete sich am nächsten Tag von seiner Familie. Weil in der Gemeinde das Gerücht die Runde machte, dass am Rande der Gemeinde Kontrollen durchgeführt wurden und sie die Männer nicht passieren ließen, reiste er im Auto auf dem Hintersitz, unter einer Decke versteckt; den Wagen fuhr eine Kollegin seiner Frau aus der Gemeinde heraus in ein Maisfeld, von dort ging er allein Richtung Grenze weiter. In Szeged angekommen hielt er bei einer Telefonkabine an und rief zuhause an, dass er es geschafft hatte. Ein Verwandter brachte am nächsten Tag seine Frau und die zwei Töchter über die Grenze - für die Familie begann ein neues Leben, in Szeged, in einer Mietwohnung.

Nur wenige unserer Interviewpartner konnten ihre Umsiedlung nach Ungarn im Voraus planen. Diese Ausnahmen waren typischerweise ehemalige Geschäftsführer in der Woiwodina, später Unternehmer in Ungarn, die Ende der 1980er Jahre die sich vertiefende wirtschaftliche Krise in Jugoslawien voraussahen und vermuteten, dass die Krise zu Krieg führen würde. Andere mussten sich aus anderen, zumeist gesundheitlichen Gründen nicht fürchten, in die Armee einberufen zu werden. So konnten sie die Umsiedlung nach Ungarn von zuhause aus planen und sich die erforderlichen Dokumente über den offiziellen Weg besorgen.

Was unseren Interviewpartnern, welche die Woiwodina in den 1990er Jahren verließen, gemeinsam war, war dass sie es nicht freiwillig taten. Die Migrationswelle in den 1990er Jahren wurde durch die Jugoslawienkriege und die darauffolgende wirtschaftliche Krise ausgelöst. Als die Kriege begannen, verfügte die Mehrheit der Gesprächspartner über eine gute Existenz. Mehrere erlebten im Gespräch rückblickend und mit einer Distanz von 20 Jahren die Bestürzung und das Unverständnis neu, mit welchen sie die damaligen Veränderungen betrachtet hatten; den Nationalismus, welcher den Alltag und die davor selbstverständlichen multiethnischen, gutnachbarschaftlichen Beziehungen vergiftete; die Gewalt des Krieges, an der sie nicht teilhaben wollten. Unsere Interviewpartner erachteten es als undenkbar, ihre alten Freunde für Feinde zu halten, auf Kollegen und Freunde die Waffe zu richten.

Verallgemeinernd formuliert SzerbHORVÁTH (2005, S. 94) in seinem Artikel zur ungarischen Kriegsliteratur in der Woiwodina: „Die Woiwodina-Ungarn (...) konnten als Minderheit diesen Krieg nicht als den ihrigen betrachten - andere Nationen kämpften miteinander um die Etablierung ihrer Nationalstaaten, um die Unabhängigkeit oder 
sei es um den ,Lebensraum“. Die Woiwodina-Ungarn landeten auf einem ,falschen Schlachtfeld'،

Soldaten, welche der Einberufung nicht entkamen und in den Krieg geschickt wurden, berichteten später von Situationen, die an Absurdität nicht zu übertreffen sind: Sie hätten in der kroatischen Baranja auf Baranja-Ungarn schießen müssen, die auf kroatischer Seite kämpften; und es sei nicht immer möglich gewesen, einen Schusswechsel zwischen Ungarn und Ungarn zu verhindern.

Die Deserteure konnten solchen Situationen entgehen. Die meisten erwarteten aber auch, dass das Fernbleiben nur ein temporärer Zustand sein werde. Sie hofften, die Konflikte würden schnell wieder abflauen, die Situation sich beruhigen, und sie könnten wieder zurückkehren.

Die Hoffnung auf ein temporäres Fernbleiben hatte in den 1990er Jahren viele ins nahe Szeged in Ungarn geführt. Damals, erinnern sich Interviewpartner, habe man auf Szegeds Straßen noch und noch Landsmänner angetroffen, welche besorgt die Nachrichten aus der „Heimat“ diskutierten und lamentierten, wann sie denn endlich zurückkehren könnten. Auch deshalb haben mehrere Familien über Monate hinweg den doppelten Wohnsitz auf sich genommen: Die Ehefrau blieb mit den Kindern zuhause in der Woiwodina und besuchte den Ehemann in Szeged oder anderswo in Ungarn; später übersiedelten aber auch sie. Die Zeit der Rückkehr zögerte sich immer mehr hinaus, man musste sich (auch) in Ungarn einrichten, leben, arbeiten - der temporäre Aufenthalt wurde schließlich zur definitiven Niederlassung in Ungarn.

Seit Beginn der 1990er Jahre gab es unter jungen Woiwodina-Ungarn auch das Phänomen der Bildungsmigration nach Ungarn. In den letzten Jahren ist die Migration zu Bildungszwecken gar zur dominanten Migrationsform geworden (ERőss et al. 2011). In den 1990er Jahren war dies noch als Folge der Kriege, durch die Embargos, die Inflation, die NATO-Bombardierungen und die lang währende Unsicherheit zu erklären. Im letzten Jahrzehnt hat sich die Bildungsmigration jedoch zu einer individuellen oder durch die Familie bewusst gewählten Berufs- und Lebensstrategie gewandelt, auch wenn Gründe wie der Mangel an Mobilität oder Wohlstand, welche auch als Migrationszwänge gedeutet werden können, weiterhin eine Rolle spielen.

Die einschränkenden Umstände, der Mangel an Berufs- und Einkommensmöglichkeiten, sind auch im Falle der Arbeitsmigration zu beobachten, wobei dies zurzeit Migrationsbewegungen in beide Richtungen betrifft, aus der Woiwodina und in die Woiwodina. Wir haben nicht nur Woiwodina-Ungarn kennengelernt, welche zur Arbeit nach Ungarn pendeln, sondern auch solche, die schon in Ungarn wohnen und von dort in die Woiwodina pendeln, weil sie dort die für sie passende Arbeit gefunden haben oder auch weil sie sich nach dem Herkunftsort sehnten. Es gibt auch nicht wenige Fälle, in denen jemand sowohl in Ungarn als auch in Serbien arbeitet und täglich, wöchentlich oder monatlich über die Grenze pendelt. Die Arbeitsmigration kann auch der erste Schritt sein, welcher zur definitiven Niederlassung in Ungarn führt, ein Element der im geographischen und gesellschaftlichen Sinne bewusst aufgebauten beruflichen Mobilität. 


\section{Generationelle Unterschiede unter den Migranten und die Rolle der Familie}

In den Geschichten der Migranten gibt es erwiesenermaßen auch generationelle Unterschiede, sei dies hinsichtlich der Gründe und Motivation für die Migration, die Umstände der Flucht oder der Übersiedlung und der durchgemachten Erfahrungen.

Die in den 1990er Jahren aufgrund des Krieges nach Ungarn übersiedelten Migranten sprechen noch heute über die Zwänge, welche die Migration ausgelöst haben und die daraus folgenden Verluste, welche auch dann eine bleibende Erfahrung sind, wenn die Betroffenen sich gänzlich in die ,ungarische Welt“ integriert haben und sich in Ungarn zuhause fühlen.

Eine in Ungarn lebende Migrantin aus der Woiwodina hat in ihrer Dissertation die Migration der in Ungarn lebenden Woiwodina-Ungarn und ihre Verwurzelung in Ungarn untersucht (Szabó 2011). Den Schmerz, die Trauer, das Gefühl der sich hinziehenden Unsicherheit und der Entwurzelung als Folge der Ankunft in einem neuen Umfeld erachtet sie als einen durch die erzwungene Migration und den Verlust materieller, seelischer und symbolischer Werte resultierenden Seelenzustand. Das Gefühl des Verlusts wird dadurch verstärkt, dass Familien und Freundeskreise sich zerstreuen, auf der ganzen Welt verstreut leben, weit entfernt voneinander; die vormals engen Beziehungen verändern sich, verblassen, neue Freunde müssen gefunden und neue Freundschaften aufgebaut werden.

Im Gegensatz zu jenen, die in den 1990er Jahren, ob jung oder alt, aus Zwang das ehemalige Jugoslawien verließen, verfügen jene Jugendlichen, welche zu dieser Zeit noch Kinder waren und in den 2000er Jahren mit Bildungszielen nach Ungarn kamen, über andere Erlebnisse in Bezug auf den Krieg und sie erleben und interpretieren ihre Migration denn auch anders. Angesprochen auf die 1990er Jahre erinnern sie sich an das Embargo und an die durch die Inflation ausgelösten wirtschaftlichen Probleme und sie betonen, dass ihre Eltern damals alles unternahmen, damit sie nichts von den Schwierigkeiten mitbekommen würden. Auf die NATO-Bombardements zurückblickend nennen sie zum Teil sogar positive Erlebnisse; dass sie sich gefreut hätten, als sie aufgrund der Unterbrechung des Unterrichts nicht hätten zur Schule gehen müssen - das waren die längsten Ferien ihres Lebens; dass man auf dem abgedunkelten Hauptplatz, wo die Dorfjugend sich traf, die erste Zigarette habe rauchen, das erste Bier habe trinken können, ,, der erste Kuss, solche Dinge“.

Die Bildungsmigration ist, wie oben erwähnt, geplanter Teil des Lebensweges und die Anpassung an ein neues Umfeld ist auch leichter, selbst wenn die Entscheidung zumeist die Familie fällt, was die Jungen auch als Zwang erleben können.

Aus den Interviews sticht heraus, dass die Rolle der Familie im Migrationsprozess entscheidend ist, die Migrationsentscheidungen werden nur selten allein gefällt. Es ist bezeichnend, dass Familien - Mann, Frau, Kinder - gemeinsam migrieren, auch wenn sich nicht die ganze Familie gleichzeitig auf den Weg macht. Die vor der Einberufung in die Armee über die Grenze flüchtenden Männer wussten und spürten das Einverständnis und die Unterstützung der Eltern, Geschwister und Ehepartnerinnen.

Das Leben der kurz- oder langfristig getrennt lebenden Familien hat aber auch viele Opfer verlangt. Gleichzeitig halfen die durch die Herausforderungen gestärkten Bande 
die schwierige Situation zu bewältigen. In einigen Fällen war die Familie selbst ein Grund für die Migration. Als Beispiel dient ein Mann, der selbst nicht geplant hatte, nach Ungarn zu ziehen, der aber seiner Frau folgte, die in Ungarn ihr Studium abschloss.

Nur in wenigen Fällen, aber doch sind einige deshalb aus der Woiwodina nach Ungarn gezogen, weil sie einen Lebenspartner oder eine Lebenspartnerin aus Ungarn fanden.

Unter den ungarischen Migranten aus der Woiwodina haben wir auch das Phänomen der sekundären Migration beobachtet. So zum Beispiel bei einer Frau, welche als gut 50-Jährige nach Szeged zog, um näher bei ihren Söhnen zu sein. Der jüngere war vor der Einberufung in die Armee nach England geflohen, während der ältere nach Szeged migrierte und später, als seine Mutter nach Szeged kam, nach Budapest weiterzog. Oder ein Ingenieur, der 1992 nach Szeged kam, nach drei Jahren in einer Mietwohnung sich eine kleine Wohnung kaufen konnte und darauf seine Tochter, welche ihre Schulbildung gerade abgeschlossen hatte, nach Ungarn holte.

Die engere oder größere Familie kann auch als ein Element der Migrantennetzwerke betrachtet werden. Unsere Interviewpartner aus der Woiwodina haben oft von Verwandten, Freunden, Bekannten oder „Bekannten eines Bekannten“ erzählt, die ihnen nach der Übersiedlung nach Ungarn geholfen hätten. Es gab ein Netzwerk, dem man sich anschließen konnte, einen Ort, an dem man Informationen erhielt, einen Kontakt, der einem half, sich im bürokratischen Labyrinth zurechtzufinden oder bei der Legalisierung des eigenen Status zu helfen.

Als eigene Interessenvertretung der Woiwodina-Ungarn kam auch die Szegediner Abteilung des VDMK, der Demokratischen Gemeinschaft der Woiwodina-Ungarn, zustande. Als sich abzeichnete, dass sich die Lage in Jugoslawien nicht schnell normalisieren würde und immer mehr Woiwodina-Ungarn nach Szeged kamen, erachteten es die Migranten als notwendig, sich zu organisieren und auf jedmögliche Art und Weise die Übersiedelnden, die flüchtenden Landsleute zu unterstützen und ihnen einen Ort zu bieten, ,an dem sie den ,Geschmack der Heimat“ finden würden“ (Szabó 2011). Ein 1992 nach Szeged gekommener Mann erinnert sich folgendermaßen:

„Wir haben versucht, einander zu finden, und dann ist das glücklicherweise auch gelungen. Ich muss sagen, dass diese Kontakte mir wichtig, sehr wichtig waren, weil wir voneinander sehr viele Informationen erhalten haben. Wir waren viele, aber in ganz unterschiedlichen Situationen, und dann ... Und jeder konnte dem anderen etwas Neues erzählen und helfen. Ich kann auch sagen, dass wir uns in finanzieller Hinsicht geholfen haben. Wir haben einander Geld geliehen, für das Unternehmen des anderen, was weiß ich ... (...) Eine Art Selbsthilfeorganisation, wie soll ich sagen, oder Beziehung, aber es hat funktioniert, und das war gut. Aber denken Sie nicht, dass das was weiß ich was für ein Unternehmen war, sondern ... Nun, in jeglicher Situation. Wenn es eng wurde finanziell, dann haben wir einander helfen können."

Eine Druckerei in Budapest zum Beispiel hat als effizientes Migrationsnetzwerk funktioniert. Selbst im Besitz von Ungarn aus der Woiwodina, hat der Betrieb fast ausschließlich Woiwodina-Ungarn beschäftigt. Dieses Unternehmen ist demnach un- 
ter Woiwodina-Ungarn bekannt dafür, dass es Arbeitsplätze bietet, beim Beschaffen der zur Niederlassung nötigen Papiere und somit bei der Lösung der Situation der Migranten hilft.

\section{Die Woiwodina-Ungarn in Ungarn - transnationale Migranten?}

BASCH et al. (1994) definieren transnationale Migranten als solche, welche in einem anderen Land leben und sich dort niederlassen, aber sich nicht von ihrem Herkunftsland abnabeln. Dies äußert sich in der Aufrechterhaltung von Beziehungen und Kontakten familiärer, wirtschaftlicher, sozialer, religiöser, kultureller und politischer Natur mit der Entsendegesellschaft. Ihre Beziehungen und privaten oder beruflichen Aktivitäten binden sie gleichzeitig an zwei oder mehrere Nationalstaaten.

Die Bindung der Migranten an ihr einstiges Zuhause, das Aufrechterhalten der Beziehungen mit den dortigen Angehörigen ist bei der Mehrheit der ungarischen Migranten aus der Woiwodina ein verbreitetes Phänomen.

Transnationalität ist aber auch keine neue Erscheinung. Transnationale Migration hat es bereits vor ihrer Konzeptualisierung und wissenschaftlichen Untersuchung gegeben. Der Unterschied zwischen den im 19. Jh. in die USA übersiedelten Migranten und den Migranten unserer Zeit liegt darin, dass die Verkehrsnetze und Telekommunikationstechnologien des 20. und 21. Jhs. es ermöglicht haben, Kontakte über große Distanzen, über Staatsgrenzen und Kontinente hinweg selbst im Alltag aufrechtzuerhalten.

Nun kann man die über politische und nationale Grenzen hinweg stattfindende Migration im weitesten Sinne als transnationale Migration betrachten (Jordan \& DüVELL 2003). Wir orientieren uns jedoch eher an der Sichtweise, dass die über nationale Grenzen hinweg erfolgende Migration an sich nicht identisch ist mit der transnationalen Migration und dass transnationale Praktiken nur auf eine Minderheit unter den Migranten zutreffen (vgl. Portes 2003, DAhinden 2005).

Das Neue in der theoretischen Konzeption der transnationalen Migration, des transnationalen sozialen Raumes liegt darin, dass sie mit dem ,,methodischen Nationalismus“ (vgl. Wimmer \& Glick Schiller 2002a, 2002b) bricht und die Vorstellung von geschlossenen Nationalstaaten auflöst. „Die transnationalen Gesellschaften (...) setzen im geographischen Sinne keine gebundenen Gesellschaften, respektive gesellschaftliche Wirksamkeiten voraus. Die Verschiebungen zwischen Lokalitäten sind nicht einmalig, sondern können auch mehrfaches Verschieben in alle Richtungen bedeuten. Auch Zukunftsperspektiven sind durch offen gelassene Möglichkeiten charakterisiert, so kommt (...) ein Schwebezustand zustande. Diese ,Schwebe“ kann sich auch konsolidieren, in anderen Fällen brechen die Migranten jedoch aus diesem Zustand heraus (...), und die Bedeutung einer Lokalität nimmt in Bezug auf private Kontakte, die Zukunftsvorstellungen und den Aufenthalt zu“ (FeIschmidT \& ZAKARIÁs 2010, S. 159).

Andere Autoren betonen, dass der transnationale Fokus in der Migrationsforschung „nicht eine Reihe von (mehr oder weniger neuen) empirischen Phänomenen, sondern eine (mehr oder weniger neue) theoretische Perspektive, ein spezifisches Verständnis von Migration repräsentiert. (...) In diesem Fall ist die Frage nicht, ob oder in welchem 
Maße eine Migrationsbewegung transnational ist, sondern wie eine transnationale Perspektive zu unserem Verständnis von Migration im Allgemeinen und von spezifischen Migrationsbewegungen beitragen kann“ (GuSTAFSON 2004, S. 68-69). Uns stellt sich demnach die Frage, ob es unter den von uns untersuchten Migrationsprozessen solche gibt, für deren Verständnis und Interpretation die transnationale Perspektive nützlich ist.

Im Verständnis von Ludger PRIES werden ,mit den Begriffen transnational und Transnationalisierung (...) grenzüberschreitende Phänomene verstanden, die - lokal verankert in verschiedenen Nationalgesellschaften - relativ dauerhafte und dichte soziale Beziehungen, soziale Netzwerke oder Sozialräume konstituieren“ (PriEs 2010, S. 13). Dauer, Intensität und Frequenz der transnationalen Kontakte, Netzwerke und Räume unterscheiden sich entsprechend deren Bedeutung im Leben des Einzelnen und ordnen sich in einer Art Reihenfolge an.

Im Falle der Woiwodina-Ungarn in Ungarn spielen zum Beispiel die über das Internet aufrechterhaltenen Kontakte mit den in der Woiwodina gebliebenen oder auf der ganzen Welt verstreuten Schulkollegen eine wichtige Rolle, oder auch die mehr oder weniger regelmäßigen Besuche im Herkunftsort.

Eine von einem in Budapest lebenden Woiwodina-Ungarn ins Leben gerufene Facebook-Community, welche Menschen unterschiedlicher Nationalität über Staatsgrenzen hinweg verbindet, funktioniert als mobilisierbares, transnationales Netzwerk. PrIEs definiert die Transnationalisierung als einen Idealtyp eines geographischen und sozialen Raumes, der über nationalstaatliche Grenzen greift; als „Konfiguration gesellschaftlicher Praktiken, Artefakte und symbolischer Systeme, welche sich über einen mindestens zwei Nationalstaaten beinhaltenden geographischen Raum erstreckt“" (PRIES 2001, S. 18).

Den von uns untersuchten, durch die ungarisch-serbische Grenze getrennten Raum, der Ungarn und die Woiwodina einschließt, können wir insofern als transnationalen Raum betrachten, als ein Teil der in diesem Raum lebenden bzw. aus diesem Raum stammenden Woiwodina-Ungarn nicht nur an einen Wohnort auf der einen oder anderen Seite der Grenze gebunden ist, sondern durch verschiedene Kontakte und Praktiken in unterschiedlicher Weise und Intensität auch an Orte und Lokalitäten im jeweils anderen Land.

Die Grenze zwischen den beiden Nationalstaaten überqueren Menschen in unterschiedlicher Frequenz und in beide Richtungen. Unter ihnen gibt es Tages- oder Fernpendler, Gymnasiasten und Studierende, welche das Wochenende bei der Familie verbringen, Dissertanten einer Doktorandenschule in Ungarn, ungarische Pädagogen in der Woiwodina, welche zur Weiterbildung nach Ungarn fahren, Schüler, Einkaufsund Wellnesstouristen, Migranten, welche ihre Eltern und Verwandten besuchen, Unternehmer, die auf beiden Seiten der Grenze geschäftliche Beziehungen pflegen - die Liste wäre erweiterbar. In diesem Raum bewegen sich Ressourcen, Güter und Symbole. Pendelnde Arbeiter bringen oder schicken ihren Verdienst nach Hause, andere brauchen das in Ungarn Ersparte für die Instandhaltung oder Renovierung des elterlichen Hauses in der Woiwodina. Das Auto der Heimkehrenden ist voll mit Geschenken, Medikamenten für die Verwandten und Bekannten in der Woiwodina, auf dem Rückweg nach Ungarn bepacken sie den Wagen mit „heimischen“ Spezialitäten und Zigaretten. 
Mit den Menschen bewegen sich im Raum auch kulturelle Güter in beide Richtungen. Um nur einige Beispiele zu nennen: Wissenschafter, welche von der Woiwodina nach Ungarn übersiedelt sind, nehmen am wissenschaftlichen und Hochschulleben in der Woiwodina regelmäßig teil; sie figurieren als Eingeladene an Konferenzen, als Jurymitglieder an studentischen Konferenzen. So, wie zu den Woiwodina-Bällen in Szeged Musiker aus der Woiwodina eingeladen werden, werden auch in Ungarn lebende Musiker aus der Woiwodina zu Hochzeiten in der Woiwodina eingeladen. Eine in Budapest lebende Künstlerin fährt regelmäßig in die Woiwodina, um als Jurymitglied an Rezitationswettbewerben teilzunehmen oder um in ihrem Geburtsort aufzutreten. Ein in Budapest lebender Kulturmanager, der einer der Organisatoren des DombosFestivals in Mali Iđoš/Kishegyes in der Woiwodina ist, baut in seinem Geburtsort Mali Iđoš/Kishegyes ein Haus.

Diesen Raum schließt eine dichte und intensive, über die Staatsgrenze stattfindende Kommunikation ein. Mobiltelefon, Internet, Skype und unterschiedliche CommunityPortale unterstützen und vereinfachen die Kontakte im Alltag über die persönlichen Treffen hinaus. Der von uns untersuchte Migrationsprozess findet im Sinne von PriES in einem transnationalen Raum statt, die Migranten bewegen sich in diesem Raum und stellen diesen Raum gleichzeitig neu her. Indes müssen wir festhalten, dass in der Realität die plurilokale, die gleichzeitig zu zwei Orten existierende intensive und dauerhafte Bindung nur auf eine Minderheit der Migranten zutrifft.

\section{Idealtypen der grenzüberschreitenden Migration und der Lebenssituationen von Migranten}

PRIES definiert vier Idealtypen der grenzüberschreitenden Migration und von Migranten basierend auf der Charakteristik der zum Entsende- und Aufnahmeland gepflegten Beziehungen sowie auf der Migrationsdauer (Pries 2010, S. 59-62). Es gilt zu betonen, dass es sich um Idealtypen handelt, die sich einzelnen Lebenssituationen nur annähern. Die Idealtypen sind auch nicht stabil, sondern dynamisch und können sich innerhalb einer Generation oder auch über Generationen hinweg verändern.

Im klassischen Modell der Emigration und Immigration machen sich die Migranten aus wirtschaftlichen oder politischen Gründen, freiwillig oder gezwungenermaßen auf den Weg. Selbst wenn sie mit ihren Angehörigen zuhause Kontakt halten, integrieren sie sich allmählich im Aufnahmeland, welches - wenn zumeist auch erst für die nächste Generation - zum neuen Zuhause wird.

Das Leben der während der Jugoslawienkriege aus der Woiwodina nach Ungarn geflüchteten Familien entwickelt sich vermeintlich gemäß diesem klassischen Modell der Emigration und Immigration. Die mit dem Herkunftsort gepflegten, oftmals sehr intensiven Beziehungen und die starke emotionale Bindung sind vor allem für die erste Generation typisch. Wir haben nur von wenigen zum Teil oder ganz in Ungarn aufgewachsenen Nachkommen erfahren, die sich noch als Woiwodina-Ungarn bezeichnen, noch Großeltern und Verwandte in der Woiwodina besuchen und bewusst die Beziehungen zur Woiwodina sowie ihre woiwodinische Identität pflegen. Die zweite 
Generation hat sich in Ungarn ganz integriert, welches sie als ihr Zuhause, als ihre „Heimat" betrachtet. Ihre Schulen, Freunde, Partner binden sie an Ungarn. Wenn sie einmal weggehen, wird bereits Ungarn das Entsendeland sein.

Die Rückkehrmigration betrifft jene Migranten, welche sich temporär zwischen den Ländern bewegen, zumeist um zu arbeiten. Sie bleiben so lange im Ausland bis sie das für notwendig empfundene Geld verdient haben. Neben den in Deutschland und in anderen westeuropäischen Ländern arbeitenden Gastarbeitern aus dem ehemaligen Jugoslawien sind hier auch die in Ungarn arbeitenden Gastarbeiter aus dem Szeklerland [Ținutul Secuiesc, ungar. Székelyföld] (vgl. PulAY 2005, Bodó 2008) und der Woiwodina zu nennen (SzABó 2003). Der Rückkehrmigrant plant keine Niederlassung im Aufnahmeland.

Aus den Interviews mit Gastarbeitern aus Feketić/Feketics und Mali Iđoš/Kishegyes, welche in den krisengeschüttelten 1990er Jahren in Ungarn arbeiteten, geht hervor, dass sie sich alle kurz- oder langfristig für die definitive Rückkehr entschieden hatten. „Sie erachten die Gastarbeit als Ausnahmesituation, die nicht Teil des Lebensentwurfs ist“" (SzABó 2003, S. 248).

Auch wir haben eine gut 50-jährige Woiwodina-Ungarin kennengelernt, welche seit 2007 in Budapest bei einem multinationalen Konzern arbeitet und mit Kolleginnen aus der Woiwodina, der Slowakei und Siebenbürgen [Ardeal, ungar. Erdély] in einem Arbeiterquartier wohnt. Einmal im Monat reist sie nach Hause, nach dem Zahltag, „, damit meine Kinder von etwas leben können“. Zwar ist sie unzufrieden mit dem Lohn und hat auch keine Aufstiegschancen an ihrem Arbeitsplatz, sie kann aber nicht in die Woiwodina zurückkehren, weil sie dort keine Arbeit findet. Sie weiß nicht, wann sie heimkehren und ihr Leben als Gastarbeiterin beenden kann.

Wir haben auch andere Fälle von Rückkehrmigration angetroffen: Manche konnten oder wollten sich nicht in Ungarn niederlassen und sind deshalb in die Woiwodina zurückgekehrt. Andere wiederum planen erst ihre Pension im Geburtsland zu verbringen.

Die dritte Form der grenzüberschreitenden Migration ist die Diasporamigration, bei der PRIES in erster Linie politische, religiöse und/oder starke Loyalitäts- und gemeinschaftliche Abhängigkeitsverhältnisse identifiziert und zum Beispiel Mitglieder von Glaubensgemeinschaften, des diplomatischen Korps, Angestellte von transnationalen Konzernen oder internationalen Stiftungen nennt. Der Diasporamigrant integriert sich zwar im physischen, räumlichen, wirtschaftlichen und vielleicht auch politischen Sinne zu einem gewissen Grad im Aufnahmeland, erachtet seine Anwesenheit allerdings als temporär, kurz- oder höchstens mittelfristig.

Diasporamigranten haben zudem eine sehr starke emotionale Bindung zum „Gelobten Land“, aus dem man sie oftmals vertrieben hat und wohin sie zurückzukehren wünschen (zum Beispiel die jüdische oder armenische Diaspora), oder auch zu ihrer „Mutterorganisation“. Eine Lebenssituation, welche diesem Idealtyp von PRIES nahekommt, konnten wir im Falle der Woiwodina-Ungarn nicht finden.

Bei Migranten, welche der transnationalen Migration zuzurechnen sind und die man „Transmigranten“ nennen könnte, ist die Migration zwischen verschiedenen 
Ländern und Orten nicht einmalig oder periodisch, sondern sie wird im Extremfall der Plurilokalität zum Normalzustand des Lebens. Das Ende der Migration, die mögliche Niederlassung, ist ein sich zeitlich hinauszögernder, allmählich stattfindender Prozess.

Diesem Idealtyp kommen jene woiwodinischen Schüler oder Studierenden am nächsten, welche zumindest einmal im Laufe ihres Lebens in Ungarn zur Schule gegangen sind oder in Ungarn studierten, um sich später dem klassischen Modell entsprechend in Ungarn oder eventuell anderswo niederzulassen oder als Rückkehrmigranten in ihr Geburtsland zurückzukehren.

$\mathrm{Zu}$ einem gewissen Grad entsprechen auch jene Migranten diesem Idealtyp, welche die Staatsgrenze zu Arbeitszwecken überqueren. Unter ihnen gibt es Rückkehrmigranten, welche nach Abschluss ihres Studiums zurückkehrten, und obwohl sie in der Woiwodina wohnen, zwei Arbeitsplätze haben, einen in Ungarn, einen in der Woiwodina. Andere wiederum leben mit ihren Familien in Szeged, pendeln aber an ihren Arbeitsplatz in der Woiwodina, wie zum Beispiel einer unserer Interviewpartner Ende Fünfzig, der 1991 nach Ungarn migrierte. Er hat alle möglichen Arbeiten angenommen, schließlich war er es aber müde, dass er keine seiner Qualifikation als Lehrer entsprechende Arbeit finden konnte und entschied sich 2003 für eine Arbeit in der Woiwodina, wohin er seither pendelt. Er hat in beiden Ortschaften Wohneigentum und plant, nach seiner Pensionierung in seinen Geburtsort zurückzukehren:

„Ich bin nicht per Zufall zurückgekehrt. Ich betrachte Magyarkanizsa ${ }^{4)}$ als mein Zuhause. Das ist der Ort, an dem ich leben kann. Nun gut, wir finden uns auch in Szeged zurecht, aber ich könnte es mir kaum vorstellen, anderswo zu leben. So habe ich das auch gesehen, als ich wegging, dass ich als Rentner zurückkomme. Nun ist es so gekommen, dass ich früher zurückkam. (...) Im Prinzip habe ich hier alles ungern zurückgelassen, mit Ausnahme des Milošević-Regimes. Die Stadt, die Menschen, die Theiß ... Ich bin nicht so gegangen, dass ich weggehen wollte ..."

Ein anderes Beispiel ist ein Intellektueller, der die Woiwodina selbst zur Zeit der Jugoslawienkriege nicht verließ, der aber bereits in den 1980er Jahren zu den damals oppositionellen intellektuellen Kreisen in Ungarn enge Beziehungen aufbaute und sich gleichzeitig intensiv ins literarische Leben in der Woiwodina einschaltete. Seine Arbeit, seine beruflichen und privaten Kontakte verbinden ihn seither sowohl mit der Woiwodina, wo er an der Universität in Novi Sad in serbischer Sprache unterrichtet, als auch mit Ungarn, wo er in Szeged promovierte und seit vielen Jahren unterrichtet. Er bewegt sich in beiden Welten und fühlt sich in beiden Welten zuhause. „Es ist mir sehr wichtig, nach Ungarn zu gehen, ich würde winseln, wenn ich nicht gehen könnte, aber es ist mir ebenso wichtig, dass ich wieder zurückkommen kann. " Der Mittelpunkt seines Lebens ist sein Geburtsort Temerin/Temerin, wo er seit seiner Kindheit lebt; „... für mein Leben habe ich mich hier verankert."

PRIES spricht bei der Charakterisierung des Idealtyps des transnationalen oder Transmigranten davon, dass dieser den Mittelpunkt seines Lebens nicht benennen kann oder nicht benennen will. Er ist gleichzeitig mit zwei Welten verbunden und fühlt sich

\footnotetext{
4) Kanjiža/Magyarkanizsa
} 
sowohl am einen als auch am anderen Ort zuhause oder heimisch. Die Transmigranten antworten auf die Frage, wo sich denn letztlich ihr Zuhause befindet, wohin es sie zieht mit „sowohl, als auch“ (PriEs 2010, S. 67).

Diesen Migranten stehen wohl jene Intellektuellen am nächsten, welche im intellektuellen, gesellschaftlichen, institutionellen und politischen System zweier Welten leben, in zwei Ländern arbeiten und über Wohneigentum und Bankkonten in beiden Ländern verfügen.

Die im Zusammenhang mit dem Idealtyp der Rückkehrmigranten erwähnte Frau, welche als angelernte Mitarbeiterin bei einem multinationalen Konzern arbeitet, verbindet mit der „ungarischen Welt“ in erster Linie ihre Arbeitskolleginnen und Mitbewohnerinnen, mit welchen sie ihre Freizeit verbringt, gemeinsam wandern geht oder nach Budapest fährt. Sie betont das Erzwungene der Migration und erlebt es als Verlust, dass sie seither nur einmal im Monat nach Hause kommt, dass die Kontakte ins Geburtsland seltener, schwächer geworden sind. In ihrer Wahrnehmung hat sich das ,sowohl hier, als auch dort“ zu einem ,weder hier, noch dort“ gewandelt.

„... ich muss dort leben, weil mich mein Arbeitsplatz bindet. Da kommt mir in den Sinn, dass so oft ich zurückkomme, das heißt einmal im Monat, sicherlich zwei bis drei Menschen in meinem Bekanntenkreis oder unter meinen Verwandten sterben. Und es ist jeweils sehr schlimm, dies auf einmal zu erfahren. Es ist so, dass ich mich weder hier noch dort zuhause fühle. Wenn ich dort bin, fehlt mir das hier, wenn ich hier bin, fehlt mir das dort."

Im Gegensatz zu dieser Frau nehmen die dem Idealtyp des transnationalen Migranten am nächsten kommenden Intellektuellen, welche sowohl an serbischen als auch an ungarischen Universitäten unterrichten und am geistigen und gesellschaftlichen Leben zweier Länder teilnehmen, ihre doppelte Einbettung als Gewinn wahr, denn sie bewegen sich vertraut in zwei Welten.

Abschließend können wir sagen, dass wir in unserem Forschungskontext nur selten auf den idealtypischen Transmigranten gestoßen sind. Die Migrationspraktiken, Beziehungen, Bindungen und Identitäten, welche den transnationalen Raum produzieren und kontinuierlich reproduzieren und welche wir in der reichen Literatur zum Transnationalismus finden, können aber beobachtet werden.

\section{Ethnische Migration - aus dem Minderheitendasein ausbrechen?}

Der konzeptionelle Rahmen und die Perspektive der transnationalen Migration im Sinne von PRIEs bieten einen möglichen Interpretationsrahmen, in erster Linie in Bezug auf die Dynamik der Migration, die als transnational bezeichenbaren Praktiken sowie die Verbundenheit der Migranten. Allerdings ist dieser Bezugsrahmen wenig hilfreich, wenn es darum geht, zu verstehen, wer die Migranten sind. Das Spezifische der von uns untersuchten Migration ist, dass Ungarn, die in den Nachbarstaaten Ungarns als Minderheit leben, nach Ungarn migrierten und migrieren. Die aus den 
umliegenden Staaten nach Ungarn gerichtete Migration ist gemäß GöDRI (2005, S. 79) „irgendwo zwischen innerer und internationaler Migration zu verorten, in einem eigenen Interpretationsrahmen, welcher die gemeinsamen historischen Wurzeln, die ethnische Identität, die sprachliche Verwandtschaft und die Rolle der kulturellen Nähe im ganzen Prozess in Betracht zieht“. Diese Form der Migration erfolgt zwar über Staatsgrenzen, aber Aufnahmegesellschaft und Migranten „gehören ein und derselben Nation an, die Einwanderer kommen - aus sprachlicher und kultureller Sicht - nicht in ein fremdes Land, sondern in ein als ihre Heimat angesehenes ,Mutterland', und die Migration bedeutet für sie nicht (zumindest gemäß den obigen Kriterien), dass sie im Aufnahmeland in den Status einer Minderheit geraten, sondern im Gegenteil, dass sie aus dem Minderheitenstatus im Entsendeland ausbrechen" (GöDRI 2010, S. 91).

So können wir festhalten, dass selbst wenn die Migration an sich in einem transnationalen Raum stattfindet respektive transnationalen Raum schafft, die Migranten ihre Geschichte oft in der Kategorie der Ethnizität erzählen und interpretieren. In den von uns untersuchten Migrationsprozessen müssen wir daher Ethnizität als ,strukturellen Faktor" und als Interpretationsrahmen für die Erfahrungen der Migranten gleichermaßen berücksichtigen.

Zur Rolle von Ethnizität in den Migrationsprozessen und zu den wichtigsten Interpretationsmöglichkeiten in diesem Zusammenhang bietet ein Beitrag von FeischmidT \& ZAKARIÁs (2010) einen guten Überblick und eine treffende Analyse. Basierend auf dieser Arbeit stellen wir kurz die verschiedenen Ansätze vor, auf welche wir uns in unserer Forschung beziehen und auf deren Basis wir unsere eigenen Forschungserfahrungen interpretieren.

Die ethnische Rückkehrmigration erlangt Bedeutung im Falle der sprachlichen, kulturellen oder religiösen Verbundenheit der Diaspora mit dem „Vaterland“. Israel und Deutschland sind in diesem Zusammenhang die am meisten diskutierten Beispiele aufgrund ihrer Diaspora- und Nationspolitik und deren Auswirkungen auf die ethnische Rückkehrmigration (FASSMANN \& MünZ 1996). Beide Länder haben die „Rücksiedlung" der im Ausland lebenden, mit einer anderen Staatsbürgerschaft ausgestatteten „Landsleute“ (im Englischen: co-ethnics) aktiv unterstützt.

In Bezug auf die nach Ungarn migrierenden Ungarn aus den Nachbarstaaten scheint Einigkeit zu herrschen, dass deren Situation speziell ist. Erstens aus historischen Gründen: Nach dem Vertrag von Trianon 1920 haben sich die Grenzen verändert, und nicht die Menschen haben das Land verlassen. Zweitens war für Ungarn eine Nationspolitik wie im Falle von Israel und Deutschland, welche die „Rückkehr“ ins sogenannte „Vaterland“ nachdrücklich unterstützt, nie charakteristisch.

Die Politiken und politischen Diskurse in Bezug auf die Ungarn in den Nachbarstaaten haben den Schwerpunkt darauf gesetzt, dass die Minderheitenungarn sich in ihrem Geburtsland verwirklichen und dort ihre nationale (ungarische) Identität bewahren. Daraus folgt, dass die unterschiedlichen ungarischen Regierungen ,weder die automatische Aufnahme der sich in Ungarn aufhaltenden, noch den erleichterten Erwerb der Staatsbürgerschaft für Ungarn aus den Nachbarstaaten“ unterstützten (ZomborY 2011, S. 220). Anders formuliert: Eine geförderte Übersiedlung der Ungarn aus den Nachbarstaaten Ungarns nach Ungarn ist im Bereich der ungarischen Nations- oder 
Migrationspolitik nicht zu finden (FEISCHMIDT \& ZAKARIÁs 2010; GöDRi 2010). Daran änderte auch die Änderung des „,Gesetzes über die ungarische Staatsbürgerschaft“ der aktuellen Regierung nichts, welche den erleichterten Erwerb der Staatsbürgerschaft für Ungarn aus den Nachbarstaaten seit Januar 2011 ermöglicht.

Wir haben nur wenige Migranten aus der Woiwodina getroffen, welche die Migration nach Ungarn als „Heimkehr“ bezeichneten. Dagegen spielten aber für die Entscheidungen der Migranten die kulturelle, sprachliche und emotionale Verbundenheit zum „Vaterland“, oftmals familiäre Beziehungen, Vorstellungen und Erwartungen eine bedeutende Rolle. Aus ihrer Sicht war es selbstverständlich, dass sie nach Ungarn zogen und nicht in ein drittes Land, wo sie wiederum als Minderheit leben würden; sie hätten gar nicht daran gedacht, anderswo zu studieren. Die im folgenden Interviewausschnitt ersichtliche Argumentation war ein wiederkehrendes Element in den Gesprächen mit den Migranten:

„Nun, ich stehe so dazu, dass wohin ich auch gehe, in welches Land auch immer ... überall, wie soll ich sagen, werden sie mich als Gastarbeiter betrachten. Es ist so, dass man seinen Beruf hat, und ich habe nie daran gedacht, mich irgendwo als Flüchtling zu melden, was auch immer, deshalb habe ich gedacht, dass es das Richtige und Logischste ist, wenn ich ins Mutterland gehe und dort mein Glück versuche."

Der ökonomischen Interpretation der ethnischen Migration gemäß ist die Migration eine Folge von Unterschieden der nationalen Arbeitsmärkte und von Möglichkeiten in Bezug auf Lebensumstände, Wohlstand und Mobilität. Menschen, die Teil einer Minderheit sind, gehen deshalb ins „Vaterland“, damit sie bessere Lebensumstände finden, zu besser bezahlter Arbeit gelangen, zu Karrieremöglichkeiten kommen. Ethnizität, die sprachliche, kulturelle Nähe funktioniert in diesem Fall als soziales und symbolisches Kapital, welches am Arbeitsmarkt eingesetzt werden kann.

Man engagiert die Woiwodina-Ungarn in Ungarn gern aufgrund ihrer Sprachkenntnisse oder aus Solidarität und Sympathie ihnen gegenüber. Bei der Untersuchung der Migration von Ungarn aus den Nachbarstaaten nach Ungarn ist diese Herangehensweise und Interpretation naheliegend, da die Mehrheit der ausländischen Arbeitskräfte in Ungarn aus den Nachbarstaaten stammt. Sie sind angelernte Arbeitskräfte von multinationalen Firmen ebenso wie Saisonarbeiter in der Landwirtschaft, Gastarbeiter in der Bauwirtschaft oder „Lohnarbeiter in privaten Haushalten“ in Budapest (für Letztere siehe zum Beispiel Bondár 2005).

Was die ungarischen Migranten aus der Woiwodina betrifft, ist es offensichtlich, dass sowohl im Falle der Beschäftigung in Ungarn als auch im Falle der Bildungsmigration der Entscheidung zur Migration ein Vergleich der in beiden Ländern vorzufindenden wirtschaftlichen Möglichkeiten sowie der Perspektiven der Mobilität und des Wohlstands vorangeht. Anders formuliert ist die Migration ein Prozess, der sowohl durch Ethnizität als auch durch ökonomische Überlegungen bestimmt ist (GöDRI 2004). In den Migrationsgeschichten vermischen sich typischerweise nicht unterscheidbar die im Hintergrund der Entscheidungen stehenden ethnischen und wirtschaftlichen Motive, das heißt, dass sich ,die mit der Ethnizität verbundenen Entscheidungen der Migranten 
und ihre wirtschaftlichen Ambitionen im Prozess der Migration herauskristallisieren und sich im Laufe dieser verändern und entwickeln“ (Pulay 2005, S. 147).

Bei der engeren Definition der ethnischen Migration (Pulay 2005) liegt der Fokus auf den die Migration auslösenden Faktoren. Hier stehen im Hintergrund der Migration die als Minderheit erfahrene Diskriminierung oder Verfolgung und die daraus folgende Angst oder aber, dass Angehörige einer Minderheit sich nur schwer in die Mehrheitsgesellschaft einzugliedern vermögen.

In den Erzählungen der ungarischen Migranten aus der Woiwodina lässt sich die Bedrohung mit dem Krieg verbinden, das Erleben der Angst, in erster Linie der Angst vor der Einberufung in die jugoslawische Armee. Obwohl die Woiwodina selbst nicht Schauplatz von Kämpfen war und der Krieg sich nicht gegen ethnische Ungarn richtete, wurde das Leben für Angehörige der ungarischen Minderheit in einem Umfeld des wachsenden Nationalismus immer schwieriger.

So wurde uns von anonymen serbischen Telefondrohungen gegenüber ungarischen Journalisten erzählt; davon, wie sich serbische Kollegen in der Mensa von den Ungarn zu distanzieren begannen; dass an der Universität die feindselige Stimmung auch den Ungarn gegenüber unerträglich wurde.

Die Lage war auch für Paare in interkulturellen Ehen ungemütlich: Serbinnen, die einen ungarischen Mann hatten, mussten sich oft die Frage anhören, „warum ihnen ein serbischer Mann denn nicht gut genug war".

Andere Interviewpartner haben auch ihre Überzeugung geäußert, dass ungarische Wehrpflichtige im Verhältnis zu ihrer Anzahl in größeren Mengen einberufen wurden - als „Kanonenfutter “ - und dass ungarische politische Repräsentanten als erste einberufen wurden.

Die Ethnizität, das Minderheitendasein hat in der Zwangsmigration der WoiwodinaUngarn denn auch eine Rolle gespielt. Sie waren Opfer des Nationalismus und sie wollten keine Position beziehen im Krieg der „großen Nationen“. Die Erzählungen der ungarischen Migranten aus der Woiwodina untermauern implizit die Gültigkeit der Sichtweise, welche ,die Zwangsmigration als ein die nationale Zugehörigkeit erodierendes und provozierendes Phänomen“ betrachtet, als Migration, welche „eine Konsequenz der Anwendung territorialer Normen auf den Nationalstaat ist, wodurch das Individuum gezwungen wird, seine nationale Identität neu zu definieren, zurechtzubiegen oder aufrechtzuerhalten“" (ZомвоRY 2011, S. 150).

Die schwache Integration in die Mehrheitsgesellschaft kann ein weiterer die Migration provozierender Faktor sein. Hinter der Bildungsmigration nach Ungarn stehen mehrere, möglicherweise auch die definitive Abwanderung unterstützende Faktoren, welche im Rahmen dieses Ansatzes interpretierbar sind: die mangelnde Kenntnis der serbischen Staatssprache, das beschränkte Bildungsangebot in ungarischer Sprache für ungarischsprachige Schüler und Studierende, die bürokratischen Hürden bei der Anerkennung der ungarischen Diplome.

Von mehreren Interviewpartnern haben wir erfahren, dass es als Angehöriger einer Minderheit „schon immer" schwieriger gewesen sei, sich zu verwirklichen; in die führenden Positionen schafften es immer die Angehörigen der Mehrheitsnation, und 
dass man als Ungar immer mehr und besser arbeiten müsse, damit die Mehrheitsgesellschaft die Leistungen anerkenne.

Es ist eine verallgemeinerbare Erfahrung und Meinung, dass es durch die Veränderung der ethnischen Struktur der Woiwodina schwieriger wurde, eine Arbeit zu finden. Einige sprachen von einer ethnischen Diskriminierung bei der Vergabe von Arbeitsplätzen. Unsere Forschungserfahrung bestätigt die Behauptung von GöDRI (2010), dass für Minderheitenungarn gesellschaftliche Mobilität, wenn auch in unterschiedlichem Maße und zu unterschiedlichen Zeiten, in den Mehrheitsgesellschaften der umliegenden Länder stets eingeschränkt war.

\section{Ethnische Migration und das Verhältnis zu Herkunftsland und ,Mutterland“"}

Ein Aspekt der ethnischen Migration, der bereits angedeutet wurde, ist das Verhältnis der Migranten zur „Heimat“. Einerseits stellt sich die Frage, inwiefern die Migranten mit dem Geburtsort oder der Gesellschaft, in welcher sie aufgewachsen sind, verbunden bleiben. Anderseits stellt sich die Frage, wie (ethnische) Migranten den Begriff der „Heimat“ für sich (er)klären.

Unter den Interviewpartnern befand sich nur eine Person, welche bewusst jeden Kontakt mit dem Geburtsland abgebrochen hat und an eine Rückkehr überhaupt nicht denkt. Es gibt viel mehr Beispiele für Personen, die von sich aus nach Ungarn übersiedelten und deren Bande zum Geburtsland sich lockerten seit die Eltern verstarben, deren Reisen ,zurück“ sich seither auf Friedhofsbesuche, in der Regel zu Allerheiligen, beschränken. Als sie von ihren Ausflügen in die Woiwodina erzählten, formulierten sie diese Erfahrung zumeist so: „Ich gehe nach Hause und komme nach Hause“. Sie fühlen sich sowohl dem jetzigen als auch dem früheren Zuhause verbunden.

„Ich bin ins Mutterland emigriert“, sagte ein in Budapest lebender Schriftsteller aus der Woiwodina, und dieser Satz verweist nicht nur auf die erzwungene Migration, sondern auch auf das spezielle Verhältnis, welches zumindest einen Teil unserer Interviewpartner, welche in Jugoslawien aufwuchsen und einen kürzeren oder längeren Abschnitt ihres Lebens dort verbrachten, mit dem „Mutterland“ Ungarn verband und verbindet. Die kulturelle Bindung war schon damals stark und intensiv, von Ungarn schleppten sie ungarische Bücher nach Hause; ein Gesprächspartner aus Temerin/ Temerin nahe Novi Sad erzählte, mit welch großer Neugier, Aufmerksamkeit und Freude die ungarische Gemeinschaft in der Gemeinde die neuen Filme aus Ungarn, die Temerin/Temerin besuchenden Budapester Schauspieler und Berühmtheiten empfing. Die Zeitschrift „Új Symposion“ veröffentlichte regelmäßig Schriften der Dichter und Schriftsteller in Ungarn, welche oft in Novi Sad zu Besuch waren. Auch haben wir oft gehört, dass die Eltern es als wichtig erachteten, dass die Kinder das „Mutterland“ kennenlernen, und man deshalb jeweils im Sommer die eine oder andere Region in Ungarn besuchte. Die damaligen Kinder betonten im Gespräch neben den positiven Erlebnissen aber auch, dass sie Ungarn als grau, heruntergekommen und arm erlebten. Es war günstig, man konnte mit 100 Deutschen Mark nicht nur 40-50 
Bücher kaufen, sondern auch im Nobelhotel Gellért in Budapest übernachten. Und wie eingangs erwähnt konnte man handeln. Mit Ironie erinnert sich ein in Budapest lebender Kulturmanager, dass die „dummen Ungarn“ seine Adidas-Schuhe von den Füßen gekauft hätten. In den 1990er Jahren kamen dann die Flüchtlinge aus der Woiwodina ", und wir wurden die Dummen “.

Die Woiwodina-Ungarn haben in Ungarn ein neues Zuhause gefunden. Dennoch hat fast jeder erfahren, ähnlich den Migranten aus Siebenbürgen, was der „Widerspruch zwischen symbolischer Aufnahme und praktischer Ausgrenzung“ bedeutet (FEISCHMIDT 2005, S. 17). Zu den Problemen im Zusammenhang mit der Legalisierung und Klärung ihrer Situation, der Beschaffung der notwendigen Dokumente für eine Aufenthalts- oder Arbeitsbewilligung haben wir viele Geschichten gehört. Wir haben auch festgestellt, dass die oftmals Jahre dauernden bürokratischen Verfahren den Verdacht der Käuflichkeit der Beamten und die Vorurteile gegenüber anderen Migrantengruppen verstärken können. Mehrere nannten ,, die Chinesen“, welche mit Anwälten und Geld ausgestattet schneller zu ihren Dokumenten gelangt seien als die Ungarn aus den Nachbarstaaten (Melegh \& Molodikova 2009; Feischmidt \& Zakariás 2010).

Als besonders schmerzhaft erlebten unsere Interviewpartner die Tatsache, dass sie in Ungarn in verschiedenen Situationen als „Serben“ oder „Jugos“ bezeichnet wurden, sei es aus Fremdenfeindlichkeit und/oder aufgrund von Unwissenheit. Dieses Phänomen wird auch im Falle der Gastarbeiter oder übersiedelten Diplomierten aus Siebenbürgen beschrieben, welche in Ungarn im Alltag, bei den Behörden oder in Diskursen mit dem „Stigma der Rumänen“ konfrontiert sind (FEISCHMIDT 2004, 2005; Fox 2005; Pulay 2005; ZaKariás 2008).

Den negativen Ausgang des Referendums von 2004 über die Vergabe der ungarischen Staatsangehörigkeit an Auslandsungarn haben auch die in Ungarn lebenden Woiwodina-Ungarn als Schlag ins Gesicht erlebt.

Interessant ist, dass Siebenbürger Ungarn und Woiwodina-Ungarn unterschiedlich mit der Stigmatisierung in Ungarn umgehen. Die ungarischen Migranten aus Siebenbürgen erleben die Kränkungen oder das ihnen widerfahrene Unrecht am Arbeitsplatz, bei Behördenverfahren, im Alltag oft als Hinterfragung ihres Ungarntums, auf welche sie mit dem Diskurs der besseren, ,echteren“ Ungarn reagieren, gemäß welchem die Siebenbürger Ungarn, die Szekler, die Auslandsungarn als die wahren Träger der ungarischen Kultur und der ungarischen Werte erscheinen, im Gegensatz zu den Ungarn in Ungarn (Fox 2005; Pulay 2005; ZaKariás 2008; Feischmidt \& ZaKariás 2010).

In den Interviews mit Woiwodina-Ungarn hingegen, auch wenn diese ihre Enttäuschung zum Ausdruck brachten - ,dort brauchten mich die Serben nicht, hier brauchen mich die Ungarn nicht “ - äußerte sich weder der "Gekränkten-Diskurs“ (ZAKARIÁs 2008), welcher die doppelte Minderheitensituation reflektiert, noch der Diskurs der „echteren“ Ungarn. Wenn es zum Vergleich kommt, so teilen die Woiwodina-Ungarn den essentialisierenden Diskurs in Ungarn, welcher die Siebenbürger Ungarn als wertvoller, als Quelle der authentischen ungarischen Kultur betrachtet, und sie sagen, dass sich die Ungarn bekanntlich ,erst“" nach der türkischen Herrschaft in der Woiwodina niederließen. 
In unseren Gesprächen stellten die Woiwodina-Ungarn die sie von den Ungarn in Ungarn trennenden symbolischen Grenzen in Narrativen einer woiwodinischen Identität dar, in welchen sie in erster Linie Unterschiede in der Mentalität, der Lebensweise und den Werten betonten. Unsere Gesprächspartner bezeichneten die WoiwodinaUngarn als offen, aufrichtig, temperamentvoll, locker, gastfreundlich; die Ungarn in Ungarn empfanden sie demgegenüber als unaufrichtig, misstrauisch, zum Selbstmitleid neigend, introvertiert, individualistisch und materialistisch. VÁRADI \& ERŐss (2013) fassten diese diskursiven Konstruktionen unter dem Titel „kulturell sind wir Ungarn, in der Mentalität Serben“ zusammen. In dieser Identitätskonstruktion erscheinen die „südlichen“ oder „balkanischen“ Züge der Woiwodina-Ungarn wie Gastfreundschaft, Temperament oder Lockerheit als Werte, welche sie in einem multikulturellen Umfeld von ihren Nachbarn anderer Nationalität - vor allem von den Serben - im Zusammenleben übernommen haben. In diesen Narrativen verorten sich die Woiwodina-Ungarn irgendwo zwischen den Ungarn und den „Südländern/Balkanern“, und aus dieser Zwischensituation, aus dem Aufeinandertreffen der beiden Kulturen und Mentalitäten konstruieren sie eine eigene Identität.

Die Identität der aus den Nachbarstaaten nach Ungarn migrierten Ungarn wird durch die starke Bindung zur Geburtsregion (Siebenbürgen, Slowakei ${ }^{5)}$, Transkarpatien [Zakarpattja], Woiwodina) charakterisiert, während die Bindung an das Geburtsland zurückgewiesen wird (GöDRI 2010). Im Falle der von uns interviewten ungarischen Migranten aus der Woiwodina haben wir auch festgestellt, dass sie zu Serbien keine Loyalität, keine seelische Bindung haben und sie Serbien nicht als ihre „Heimat“ betrachten. Unter den Älteren haben sich einige auch als jugoslawische Ungarn bezeichnet, weil sie ihre Kindheit, Jugend oder einen anderen Lebensabschnitt in Jugoslawien verbrachten oder weil sie vor dem Krieg gern dort gelebt hatten. „Es war gut, Jugoslawe zu sein".

Die Mehrheit empfindet eine emotionale Bindung in erster Linie zur Woiwodina und auf lokaler Ebene zur Geburtsgemeinde oder zum Geburtsort. Die woiwodinische „Heimat" kommt in den Narrativen auf zweierlei Arten vor: Die Erzählungen zeugen einerseits von der Erinnerung und der starken Bindung an die Natur, das elterliche Haus, die Menschen, das Milieu, die Stimmungen und Erlebnisse, andererseits berichten sie von der radikalen Veränderung der woiwodinischen „Heimat“. Praktisch jeder Migrant hat davon erzählt - die einen mit Schmerz, die anderen mit Resignation, die dritten aufgebracht - wie stark sich die Welt ihrer „Heimat“ verändert habe. Die Zahl der Ungarn nehme ab, die Zahl der Serben nehme zu; diese gestalteten die Ortschaften nach ihren Vorstellungen um, nähmen die öffentlichen Plätze in Besitz; in den Straßen, den Kaffeehäusern, den Geschäften werde das ungarische Wort immer seltener; Novi Sad und Subotica/Szabadka verlören ihr Gesicht und ihre Geschichte aus der Zeit der Monarchie und würden zu „balkanischen“ Städten.

\footnotetext{
5) Im Königreich Ungarn wurde das Gebiet der heutigen Slowakei als „Oberungarn“ [ungar. Felvidék] bezeichnet. Diese Bezeichnung lebt im traditionellen Zusammenhang fort.
} 


\section{Schlussfolgerungen}

Die Migration von Woiwodina-Ungarn nach Ungarn ist seit den Jugoslawienkriegen in den 1990er Jahren ein bedeutendes Phänomen, auch wenn sich Motive und Form der Wanderung in den letzten 20 Jahren verändert haben. Seien es die während der Kriege vor der Einberufung in die jugoslawische Armee geflüchteten Männer, jene, die aufgrund der wirtschaftlichen Krise migrierten oder mangels Arbeitsplätzen nach Ungarn pendeln, oder die in Ungarn studierenden Jugendlichen, sie alle haben ihr Geburtsland, oder ihre Geburtsregion Woiwodina für kürzer oder länger in Richtung Ungarn verlassen.

Anhand der von PRIES definierten Idealtypen grenzüberschreitender Migration haben wir diskutiert, inwiefern die ungarischen Migranten aus der Woiwodina als Emigranten und Immigranten im klassischen Sinne, als Rückkehrmigranten oder als transnationale Migranten verstanden werden können. Wie die vielen Beispiele verdeutlicht haben, gibt es darauf keine eindeutige Antwort. Wir haben daher versucht zu zeigen, dass der allgemeine Trend in der Wissenschaft zur Transnationalisierung der Migration seine Tücken hat und dass im Falle der ungarischen Migranten aus der Woiwodina nur für eine Minderheit die Bezeichnung „transnationale Migranten“ im engsten Sinne zutrifft. Zwar findet man transnationale Praktiken und Lebensformen, und dies nicht in geringem Maße, letztlich ist es aber doch eine Minderheit, welche sich nicht doch früher oder später in eine der anderen Kategorien einordnen lässt und die klassische Emigration/Immigration oder Rückkehrmigration wählt. Transnationale Migranten sind sie ,auf Zeit“. Vielmehr findet sich das Transnationale längerfristig im ,seelischen Zustand“, in der emotionalen Bindung, bestens ausgedrückt im Zitat eines Woiwodina-Migranten, der in Ungarn lebt und gelegentlich in die Woiwodina reist: „Ich gehe nach Hause und komme nach Hause“.

Schließlich haben wir versucht, mit dem Konzept der ethnischen Migration der Charakterisierung der Migration der Woiwodina-Ungarn in Ungarn näherzukommen. Durch die kulturelle, sprachliche Nähe zur Migrationsdestination sind sie in Ungarn in einer anderen Situation als Migranten, welche in ein völlig fremdes Land migrieren. Die Woiwodina-Ungarn sind in Ungarn nicht „Fremde“ im klassischen Sinne, auch wenn sie im Alltag mit Situationen konfrontiert werden, welche das Gegenteil bezeugen, wenn sie zum Beispiel als „Serben“ oder ,Jugos“ bezeichnet werden. Für die meisten Interviewpartner war es selbstverständlich, dass sie ihr Geburtsland Richtung Ungarn und nicht anderswohin verließen. Die enge emotionale Beziehung zum „Mutterland Ungarn“verstärkt letztlich wohl auch das Gefühl des „,sowohl, als auch“, des „sowohl hier, als auch dort“, wodurch viele längerfristig in einem emotionalen „Schwebezustand“ verharren, auch wenn sie sich physisch für eine Niederlassung in Ungarn oder eine Rückkehr in die Woiwodina entschieden haben. 


\section{Literaturverzeichnis}

Basch L., Glick Schiller N., Szanton Blanc Ch. (1994), Nations Unbound. Transnational Projects, Postcolonial Predicaments and Deterritorialized Nation-States. London - New York, Routledge.

Bodó J. (Hrsg.) (2008), Migrációs folyamatok - közösségi megjelenítések [Migrationsprozesse - gemeinschaftliche Darstellungen]. Csíkszereda, Státus Kiadó.

Bondár A. (2005), Női migráció és változó nemi szerepek. Széki asszonyok Budapesten [Weibliche Migration und sich ändernde Geschlechterrollen. Frauen aus Szék in Budapest]. In: Feischmidt M. (Hrsg.), Erdély-(de)konstrukciók. Tabula könyvek 7, S. 163-183. Budapest - Pécs, PTE Kommunikáció- és Médiatudományi Tanszék.

DAHINDEN J. (2005), Contesting transnationalism? Lessons from the study of Albanian migration networks from former Yugoslavia. In: Global Networks, 5, 2, S. 191-208.

Erőss Á., Filep B., RÁcz K., TÁtrai P. VÁradi M.M., Wastl-Walter D. (2011), Tanulmányi célú migráció, migráns élethelyzetek: vajdasági diákok Magyarországon [Bildungsmigration, Lebenssituation von Migranten: Studierende aus der Woiwodina in Ungarn]. In: Tér és Társadalom, 25, 4, S. 3-19.

Fassmann H., Münz R. (Hrsg.) (1996), Migration in Europa. Historische Entwicklung, aktuelle Trends, politische Reaktionen. Frankurt am Main, Campus Verlag.

Feischmidt M. (2004), A határ és a román stigma [Die Grenze und das ungarische Stigma]. In: Kovács N., Osvát A., Szarka L. (Hrsg.), Tér és Terep. Tanulmányok az etnicitás és identitás kérdésköréből, S. 43-58. Budapest, Akadémiai Kiadó.

Feischmidt M. (2005), A magyar nacionalizmus autenticitás-diskurzusainak szimbolikus térfoglalása Erdélyben [Die symbolische Raumaneignung der Authentizitätsdiskurse des ungarischen Nationalismus in Siebenbürgen]. In: Feischmidt M. (Hrsg.), Erdély-(de) konstrukciók. Tabula könyvek 7, S. 7-32. Budapest - Pécs, PTE Kommunikáció- és Médiatudományi Tanszék.

Feischmidt M., ZaKariás I. (2010), Migráció és etnicitás. A mobilitás formái és politikái nemzeti és transznacionális térben [Migration und Ethnizität. Formen und Politiken der Mobilität im nationalen und transnationalen Raum]. In: FeIschmidt M. (Hrsg.), Etnicitás. Különbségteremtő társadalom, S. 152-169. Budapest, Gondolat-MTA Kisebbségkutató Intézet.

Fox J.E. (2005), Vándorló nemzet(i) - identitások. Erdélyi vendégmunkások Magyarországon [Wandernde Nation(en)-Identitäten. Siebenbürgische Gastarbeiter in Ungarn]. In: FeISCHMIDT M. (Hrsg.), Erdély-(de)konstrukciók. Tabula könyvek 7, S. 103-122. Budapest - Pécs, PTE Kommunikáció- és Médiatudományi Tanszék.

GöDRI I. (2004), Etnikai vagy gazdasági migráció? Az erdélyi magyarok kivándorlását meghatározó tényezők az ezredfordulón [Ethnische oder ökonomische Migration? Die zentralen Faktoren der Auswanderung siebenbürgischer Ungarn zur Jahrtausendwende]. In: Erdélyi Társadalom, 1, S. 37-54.

GöDRI I. (2005), A bevándorlók migrációs céljai, motivációi és ezek makro- és mikrostrukturális háttere [Migrationsziele und -motive der Einwanderer und deren makro- und mikrostrukturelle Hintergründe]. In: GöDri I., TóTH P.P. (Hrsg.), Bevándorlás és beilleszkedés, S. 69-131. Budapest, KSH Népességtudományi Kutatóintézet.

GöDRI I. (2010), Bevándorlás és etnicitás - összefüggések nyomában [Einwanderung und Ethnizität - auf den Spuren von Zusammenhängen]. In: HÁrs Á., Tóth J. (Hrsg.), Változó migráció - változó környezet, S. 87-124. Budapest, MTA Etnikai-nemzeti Kisebbségkutató Intézet. 
Gustafson P. (2004), More or Less Transnational: Two Unwritten Papers. In: Povrzanović FryKman M. (Hrsg.), Transnational Spaces: Disciplinary Perspectives, S. 64-76. Malmö, Malmö University.

Jordan B., Düvell F. (2003), Migration: the Boundaries of Equality and Justice. Cambridge, Polity Press.

Melegh A., Molodikova I. (2009), Bevándorlói interjúk elemzése [Analyse von Interviews mit Einwanderern]. Working Paper, Budapest, KSH.

Portes A. (2003), Conclusion: Theoretical Convergencies and Empirical Evidence in the Study of Immigrant Transnationalism. In: International Migration Review, 37, 3, S. 874-892.

PrIEs L. (2001), The approach of transnational social spaces. In: PrIES L. (Hrsg.), New Transnational Social Spaces. International migration and transnational companies in the early twenty-first century, S. 3-33. London - New York, Routledge.

Pries L. (2010), Transnationalisierung. Theorie und Empirie grenzüberschreitender Vergesellschaftung. Wiesbaden, VS Verlag für Sozialwissenschaften/Springer Fachmedien Wiesbaden $\mathrm{GmbH}$.

Pulay G. (2005), A vendégmunka mint életforma. Széki építőmunkások Budapesten [Gastarbeit als Lebensform. Bauarbeiter aus Szék in Budapest]. In: Feischmidt M. (Hrsg.), Erdély-(de) konstrukciók. Tabula könyvek 7, S. 143-162. Budapest - Pécs, PTE Kommunikáció- és Médiatudományi Tanszék.

Szabó Á. (2003), Vajdaság - Kishegyes és Feketics. Vendégmunka és migrációs potenciál a két településen [Woiwodina - Kishegyes und Feketics. Gastarbeit und Migrationspotenzial in den beiden Gemeiden]. In: ÖRKÉNY A. (Hrsg.), Menni vagy maradni? Kedvezménytörvény és migrációs várakozások, S. 241-255. Budapest, MTA.

Szabó E. (2011), Többség? Kisebbség? [Mehrheit? Minderheit?]. Záródolgozat, Budapest, Semmelweis Egyetem/Károli Gáspár Református Egyetem Sapientia Szerzetesi Hittudományi Főiskola.

SZERBHORVÁtH Gy. (2005), Háború, irodalom - háborús irodalom a vajdasági magyar irodalomban (1991-2005) [Krieg, Literatur - Kriegsliteratur in der woiwodina-ungarischen Literatur (1991-2005)]. In: Regio, 3, S. 89-119.

VÁRADI M.M., ERŐsS Á. (2013), „Kulturálisan vagyunk magyarok, mentalitásban szerbek vagyunk szerintem, igen“. Magyarországon élő vajdasági magyar migránsok és a jugóbuli [„,Kulturell sind wir Ungarn, der Mentalität nach Serben, jawohl““. In Ungarn lebende ungarische Migranten aus der Woiwodina und die Jugopartys]. In: Tér és Társadalom, 2, S. 55-76.

Wimmer A., Glick SchilLER N. (2002a), Methodological Nationalism and the Study of Migration. In: Archives of European Sociology, XLIII, 2, S. 217-240.

Wimmer A., Glick Schiller N. (2002b), Methodological Nationalism and Beyond: Nation-State Building, Migration and the Social Science. In: Global Networks, 2, 4, S. 301-334.

ZAKARIÁs I. (2008), Identifikációs narratívák Magyarországra áttelepült erdélyi diplomások élettörténeteiben [Identifikationsnarrative in den Lebensgeschichten von nach Ungarn übersiedelten Studienabgängern aus Siebenbürgen]. In: Regio, 3, S. 135-167.

Zombory M. (2011), Az emlékezés térképei. Magyarország és a nemzeti azonosság 1989 után [Karten der Erinnerung. Ungarn und nationale Identität nach 1989]. Budapest, L'Harmattan. 